\title{
ОПОЛЗНЕВЫЕ ЗОНЫ И ПАВОДКОВЫЕ ПЛОЩАДИ В БАРНАУЛЬСКОМ ПРИОБЬЕ: (СИНЕРГИЧЕСКИЕ АСПЕКТЫ)
}

\author{
Б. Н. Лузгин \\ Алтайский государственный университет, Россия \\ Поступила в редакиию 25 марта 2019 г.
}

\begin{abstract}
Аннотация: Исследован характер синергических связей оползневых подвижек и паводковых наводнений долины реки Обь в окрестностях города Барнаул Алтайского края, как опасных природных явлений. Акцентировано внимание на детализацию комплекса природных особенностей соответствующих обстановок, игнорирование которых обусловил перманентный системный рост затрат труда и средств на мало эффективные методы снижения их экологического риска. Единственным рациональным решением проблемы является ликвидация пригородного пос. Затон, как места постоянного проживания населения.
\end{abstract}

Ключевые слова: Обь, речная долина, Пра-Обь, зоны структурной перестройки левосторонней и правосторонней пойм, оползни, наводнения, взаимозависимость наводнений и оползневых сходов.

\section{Landslide zones and flood area in Barnaul Ob: (Synergetic aspects)}

\section{B. N. Luzgin}

\begin{abstract}
The nature of synergetic relationships of landslide movements and floods in the valley of the r. Ob in the vicinity of the city of Barnaul, Altai Territory, as dangerous natural phenomena. Attention is focused on the detailing of the complex of natural features of the respective environments, the underestimation of which has led to a permanent systemic increase in the cost of labor and funds for little effective methods of reducing their environmental risk. The only rational solution to the problem is the elimination of the suburban village Zaton, as a place of permanent residence of the population.
\end{abstract}

Key words: Ob, river valley, Pra-Ob, zones of structural adjustment of left-side and right-side floodplains, landslides, floods, interdependence of floods and landslide descents.

\section{ВВЕДЕНИЕ}

Паводки Оби с неизменным постоянством приводят к активизации оползневых процессов вдоль высокого левобережья реки в районе города Барнаул и, в то же время, к затоплению низменных пространств на противоположных берегах, включая пригородный поселок Затон. Каждый раз после разгула вешних вод с завидным постоянством продолжается укрепление оползающих берегов и восстановление размытых прибрежных насыпей. Все это происходит с постоянно растущими затратами труда и средств.

\section{ЗОНЫ ПАВОДКОВЫХ НАВОДНЕНИЙ РЕКИ ОБЬ}

Географическая позиция этой местности определяется размещением основной массы городских строений на высоком левом берегу Оби в районе

(C) Лузгин Б.Н., 2019 резкого коленного разворота основного водотока с меридионального направления на юге к западному на севере. Этот региональный геоморфологический уступ, означающий границу Приобской возвышенности, почти на сотню метров возвышается над уровнем низменной поверхности обширной Обской долины, окаймляющей ее с востока и севера [1]. Долина реки имеет здесь ширину порядка 15-20 км в своем меридиональном звене и вдвое меньше в северной широтной части. Русло основного потока реки шириной 50-100 м приурочено к эродируемому высокому левому берегу.

Боковые притоки реки Обь поперечны ее руслу и долине и асимметричны: более протяженны в правобережье и укорочены слева. Поэтому уклоны левых притоков относительно более круты в своей приустьевой части и «прямоточны» в сторону долины главной реки. Принципиально иная картина наблюдается в правобережье Оби, где верховья и средние течения рек-притоков общей ши- 
ротной направленности характеризуются слабыми уклонами. А нижние их участки в пределах общей долины реки Обь образуют запутанный узорчатый рисунок разно ориентированных и разновозрастных водотоков, сочетающихся с петельчатыми речными изгибами различной кривизны [4]. Доминирующими являются речные протоки меридионального плана, соответствующие общей ориентировке долины Оби. Более фрагментированы здесь широтные проточные системы, представляющие собой реликты рек-притоков. Развитость тех и других и их густота во многом зависят от последовательности и истории формирования данной гидросети. В целом более ранними являлись русловые потоки меридиональной направленности, образовавшиеся по типу разветвленных русел. Более поздней в обском долинном комплексе осадков по отношению к ним оказалась структурная перестройка эрозионных систем приточными реками, впадающими в основную водную артерию.

Особая роль в этом лабиринте проток принадлежит наиболее устойчивым последовательным позициям общей системы, существовавшей ранее Пра-Оби. Здесь нами на основе дешифрирования космических фотоматериалов [5] и высотных аэросъемок [7] были отслежены фрагменты прежнего русла этой крупной палеореки.

Соотношение степени развитости проток двух указанных довлеющих позиций может быть проиллюстрировано на примере реки Бобровки, узкая долина которой при входе из равнинного в долинный ландшафт Оби с трудом трассируется в качестве собственно Бобровской протоки в сложном переплетении изобилующих здесь других проточных систем. Происходит это таким образом, что их совокупное русло смещается от выхода собственно реки Бобровка к долине реки Оби до впадения ее в Обь, теперь уже в качестве Бобровской протоки, на протяжении свыше 20 км. Аналогичная ситуация прослеживается и для соседней к востоку протоки реки Талой, которая всецело принадлежит долинному ландшафту реки Обь. Ориентировка той и другой проток соответствует положению в современной долине Оби древнего русла Пра-Оби. Это было еще исстари подмечено местным населением и закрепилось в названиях ряда крупных проток - Старая Обь (на правом берегу современного русла Оби вдоль северной окраины Барнаула и перед Обским водохранилищем в районе пос. Каргополово), Старица, Старый Алей в районе Троицк-Калманка. Сложная долинная система проток сопровождается не менее запутанной вязью размещения старичных озер ряда последовательных стадий формирования.

Все перечисленные элементы гидросети долины реки Обь между собой тесно и закономерно связаны [7]. Нет никакого сомнения, что та же самая палеодолина Пра-Оби в ее собственном литологическом комплексе осадков, перекрытых с поверхности более поздними пойменными отложениями, участвует в общем водотоке ее долинных систем, отличаясь от окружающего фонового потока лишь более интенсивными параметрами водопереноса. Вероятно, по плотности размещения озер-стариц можно делать заключения и о наиболее активных участках и периодах перестроек гидросистем реки.

Поэтому преобладающим направлением стока поверхностных и грунтовых вод здесь служит общий уклон тальвега главной реки региона и, в меньшей степени, общий западный наклон от правобережья долины Оби к расположению ее современных русел.

\section{ОСОБЕННОСТИ ОПОЛЗНЕВЫХ ОБСТАНОВОК РЕГИОНА}

Контрастные гидродинамические обстановки по разным берегам Обской гидросистемы являются теми исходными природными факторами, предопределяющими различия и масштабы опасных природных явлений в районе окрестностей города Барнаул.

Проблемы оползневой активности реки Обь в Алтайском крае особенно остры здесь, в районе крутого коленного изгиба реки по периферии высокого берега Приобской возвышенности. При этом следует учитывать не только природные особенности этого района, но и его высокую техническую загруженность. Только вдоль бровки берегового склона Оби сосредоточено около 20 промышленных предприятий машиностроения, химической, легкой промышленности и энергетики. В настоящее время почти $40 \%$ этих сооружений и обслуживающих коммуникаций находится в аварийном состоянии. Кроме того, развитие Барнаула происходило таким образом, что более 70 инженерных сооружений, построенных в 1960-1980-е годы, оказались сосредоточены на склонах и пойме.

Практически весь левый берег в пределах города и пригородных селений характеризуется широким развитием оврагов и оползневых цирков. Причинами этих явлений выступают - крутые и обрывистые склоны высокого борта Оби; мощная рыхлая толща почти горизонтально залегающих 
осадочных слоев различной устойчивости; водонасыщенность и водопроводность; сезонная изменчивость уровневого режима Оби, провоцирующего эродирование прибрежных террасированных уступов берега. Дополнительно на высоком левобережье реки к естественному обводнению дополняется обводнение антропогенное.

Склон долины обрывается в сторону русла р. Обь уступом высотой 60-120 м с углами наклона свыше $30-50^{\circ}$ и к тому же характеризуется высокой изрезанностью за счет ложбин стока и овражных логов.

Все это с учетом повышенной суффозионности отдельных горизонтов слоистой рыхлой толщи, слагающих склон долины, приводит к местному наклонению стратиграфических пачек в сторону основной долины Оби. С увеличением наклона дренаж грунтовых и подземных вод усиливается, что создает исходные благоприятные условия для возникновения оплывин и оползней.

Оползневая зона в левобережной части реки Обь представлена придолинной полосой, следующей по периметру Приобской возвышенности с севера и запада [2]. Средняя ее ширина около 250 м. В ее тыльной части нередко встречаются суффозионные блюдца и воронки, иногда группирующиеся в цепочки. Этому благоприятствует развитие здесь мощной пачки горизонтально залегающих рыхлых четвертичных толщ аллювиальноозерного происхождения, перекрытых лессовидными эоловыми осадками голоцена. Местами наблюдаются трещины срыва. У высокого обрыва (более 60 м) развиты открытые в сторону долины реки овраги и лога, достигающие 750 м в длину.

Практически весь берег Оби изрезан оползневыми цирками. Общая протяженность городской оползневой зоны свыше 20-25 км. Ежегодно здесь происходит до 30 оползневых подвижек. За предыдущие 25-50 лет сошло более 300 оползней объемом от 10 до 200 тыс. м³. Имеются заломы до 800 м по фронту и до 1,5 млн м 3 по объему. Преобладающая часть оползней асеквентна, с оползневыми подвижками на разных уровнях плейстоценовых отложений. Отступление бровки долины составляет от 1 до 35 м ежегодно.

Существенное значение для уяснения процессов влияния водных речных потоков на сопровождающие их деятельность опасные природные явления с позиции синергетики - «одновременного совместного проявления кооперативных процессов» [14] - имеет организация гидродинамического режима речной водной среды. Решающую роль в характере структуры речных потоков играет турбулентность - силовая векторная неупорядоченность движения жидкости.

Активность водного потока отчасти определяется характером ее дифрагирования, по закону изменения скорости с глубиной. В нижней части движущегося водного потока доминируют донные течения, нередко отклоняющиеся от направленности стержневого потока поверхностных вод на существенные угловые величины [16].

Механизм подобного преобразования поточных водных струй детально исследован представителями геологических дисциплин и, в частности, генетиками россыпных месторождений полезных ископаемых. При меандровом поведении русла реки происходит чередование зон размыва (боковой эрозии) берегов на их вогнутых излучинах и «намыва» волглых осадков у выпуклых берегов, причем возникающие донные течения ориентированы так, что снос взвешенного материала направлен от выпуклой к вогнутой стороне реки. Вместе с тем, скорость течения меняется и с изменением живого сечения потока, увеличиваясь на интервалах сужения и обмеления русла, создавая в этих случаях водовороты.

Важно обратить внимание и на характер воздействия водных потоков с противодействием им береговых литологических сред, эродируемых водными струями и являющимися преградами на пути их движения.

Разрушение вогнутых берегов, их размыв в случае высокого половодья приводит к активизации оползневых явлений. И, наоборот, «намыв» вогнутых берегов ведет к образованию все более тонких слоев аккумулятивных осадков, образующих отмели и косы со все уменьшающейся долей взвесей обломочного материала и возрастанием роли собственно водных масс.

Еще одним важным морфологическим элементом подобных ситуаций служат перекаты - подводные гряды, часто пересекающие русла рек по диагонали. Ими обособляются самые глубокие участки речного русла - плесы, примыкающие к вогнутой зоне берегов, разделяя их верхние и нижние побочни. Характерна смена донных потоков на контрастно ориентированные по отношению к стержневому течению речного потока, по существу - это своеобразный водораздел [16].

Возведение береговых насыпей и дамб, особенно интенсивное в условиях блуждающих и разветвленных рек, имеет давнюю историю. Знание этого феномена широко использовалось не только с 


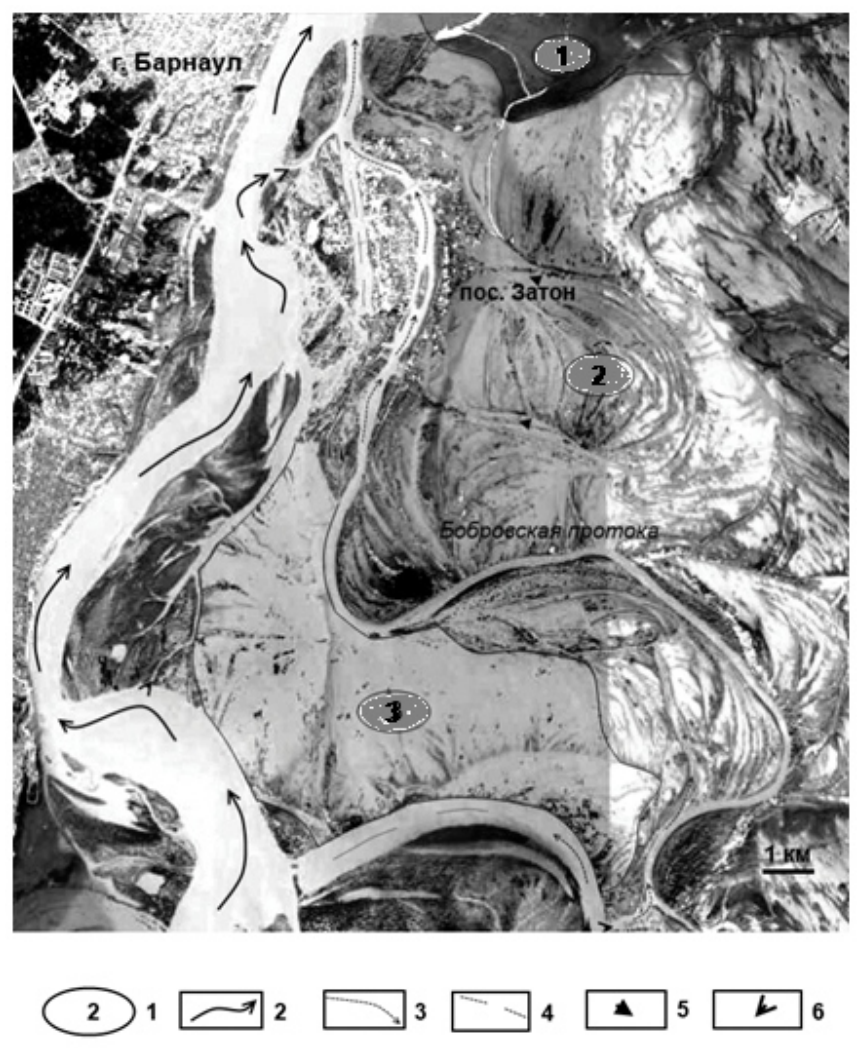

Рис. Гидролого-географическая ситуация Затонского района Барнаульской пригородной зоны

Ландшафтные зоны: 1 - водно-болотные угодья, 2 - ложбинно-гривистый пойменный рельеф $[12,15]$ лингоидно-конволютного рисунка $[4,11,13]$ - «тонкие временные срезы» [13], 3 - площади регулярных паводковых подтоплений.

Направления потоков: 2 - динамично активных речных вод, 3 - относительно «пассивных» вод проточных систем, 4 - полузастойных вод заводей, 5 - промоины, 6 - места прорывов речных вод в смежные водные системы.

целью защиты объектов от возможных последствий при сильных наводнениях, но также для осуществления агрессивных планов по разрушению нежелательных объектов на смежных противобережных «чужих» территориях. Примером этих действий являются так называемые «дамбовые войны» между Китаем и Вьетнамом, когда специально возводились искусственные береговые преграды, способствующие направлению бурных водных потоков на размыв прибрежной полосы соседнего государства. Используются эти приемы и в настоящее время [9].

Русловой поток речных вод естественно сопровождается соответствующим дренажом подземных вод долинных отложений реки Обь, относимых М. И. Львовичем к литогенному звену водного круговорота [8]. В общем, он проявляется в объемах, уступающих открытому водному потоку несколько менее его трети. Эти подземные воды структурно не однородны, в зависимости от фациальной принадлежности и проницаемости осадков данных конкретных обстановок и направлений.
Вероятно, наибольшая проточность долинных отложений Оби должна быть свойственна более грубым русловым осадкам системы потоков Пра-Оби, занимавшей прежде правую присклоновую часть современной речной долины, погребенную ныне под более поздними наносами. Меньшей водопроводимостью характеризуются бывшие разветвленные потоки реликтовой речной системы, наследуемые протоками типа Бобровской, Талой, Лосихи. И ряда им подобных, которые питаются за счет поступления вод из равнинных речных притоков. Кроме того, следует учитывать сеть мелких и коротких побочных речных перемычек, соединяющих их с основным русловым потоком долины реки Обь в единую сложную систему.

Важной ситуационной характеристикой динамики подземных долинных водотоков являются зоны крупных структурных перестроек, обусловленных сменой позиции основных русловых систем в пределах долины Оби правосторонних левосторонними, и наоборот. В частности, особое внимание привлекает резкое изменение положения 
русла Оби по отношению к ее долине с левосторонней на правостороннюю на протяжении свыше 20 км - единственный случай на всем пространстве меридиональной части этой обширной речной долины, которая обычно выдержанно прослеживается в данном направлении по длине около 130 км.

Левобережная часть долины Оби резко отличается по структуре приточных систем, характеризуясь здесь преобладанием ветвей широтных приток и сопровождающих их старичных озер, в отличие от правобережных долинных пространств, на которых преобладают меридионально ориентированные протоки. В зоне южной перестройки от правобережных к левобережным руслам их современное прибортовое положение в значительной своей части наследует примерную позицию прежних пра-обских потоков.

\section{ОПОЛЗНЕВЫЕ И ПАВОДКОВЫЕ ОПАСНОСТИ}

Существенное значение для уяснения процессов влияния водных речных потоков на сопровождающие их деятельность опасные природные явления, с позиции синергетики [14] - «одновременного совместного проявления кооперативных процессов», имеет организация гидродинамического режима речной водной среды. Решающую роль в русловых процессах играет турбулентность - векторная неупорядоченность движения жидкости.

Из приведенных выше описаний о структурах и перестройках речной гидросети Оби следует ряд выводов о паводковых обстановках в районе пос. Затон, определяющих здесь синергетичность оползней и речных разливов (рис.). Чем выше уровень подъема вод в реке, тем интенсивней и масштабней происходит обрушение крутых склонов долины реки.

Во-первых, это совокупность разрушающих и аккумулирующих действий водных потоков в разных поперечных сечениях реки, отражающих стрежневые русловые течения в случае устойчивых и высоких прибрежных преград. Важным элементом этих ситуаций служат эффекты отраженных от препятствий струй с формированием косых по отношению к исходным донным потокам, которые активно участвуют в образовании грив перекатов, прибрежных валов и промоин. Поселок Затон как раз и находится в зоне подобных подтоплений, после отбоя в этом направлении водных струй высоким левобережьем.

Во-вторых, существенную роль в зонах подтоплений и затоплений играет характер взаимосвязей всей современной гидросети - русел, рукавов, про- ток и озерных стариц, а также совокупности затонных обстановок, когда односторонне отшнурованные участки прежних речных рукавов ориентированы в направлении противоположном уклонам существующих русел. В том числе здесь весомо и значение различных водных перемычек, расположенных ближе к головам речных потоков, по которым в периоды паводков значительно возрастает объем поступающих приточных вод.

В этом отношении устьевая зона наиболее крупного правостороннего притока - река Бобровка как раз приходится непосредственно на поселок Затон. По существу здесь сосредоточены три весьма сближенных параллельных водных потоков единой направленности: основного русла Оби, его крупного побочного рукава и Бобровской протоки. И к этому добавляется затонный отрезок той же ориентировки. Немудрено, что в периоды крупных паводков сам поселок становится по существу островным поселением. Притом что площадь водосборного бассейна самой Бобровки здесь составляет более трети правосторонней поймы Оби.

Так же следует учитывать, что водоносность правой стороны долины реки Обь здесь значительно усиливается за счет нахождения этого участка в зоне перестройки структуры долины правосторонней в левостороннюю. Эта перестроечная зона в описываемом интервале характеризуется существенным обилием соответственно ориентированных реликтовых систем старичных озер, которые сами по себе уже являются свидетельством подобных структурных преобразований.

Еще один немаловажный фактор, благоприятствующий развитию наводнений в районе поселка Затон, обусловлен тем, что ход прежних структурных трансформаций в этой зоне по существу является унаследованным, подобным существующему в настоящее время.

Таким образом, выбор места стационарного поселения был предельно иррациональным. Представленный механизм паводковых наводнений в районе поселка Затон свидетельствует о системном характере их проявлений и высокой степени риска повторений с высокими уровнями подъема вод. Принимаемые меры по его минимизации не могут быть отнесены к эффективным. Необходим поиск альтернативного решения проблемы.

Кардинальным в этом отношении, вероятно, является лишь ликвидация поселка как объекта постоянного проживания населения. В качестве подготовительной стадии, очевидно, следует создать комплексную программу целенаправленно- 
го систематического мониторинга, с целью прогнозирования последовательной корреляции действий по текущему регулированию производства ликвидационных работ, с учетом степени опасности.

\section{СПИСОК ЛИТЕРАТУРЫ}

1. Адаменко О. М. Предалтайская впадина и проблемы формирования предгорных опусканий / О. М. Адаменко. - Новосибирск : СО Наука, 1976. $184 \mathrm{c}$.

2. Девятаева В. В. Экзогенные геологические процессы на территории Алтайского края / В. В. Девятаева // География и природопользование Сибири. - 2001. Вып. 4. - С. 264-268.

3. Лузгин Б. Н. Парагенетические связи аллювиальных и эоловых процессов в Верхнем Приобье / Б. Н. Лузгин // География и природопользование Сибири. - 2009. - Вып. 11. - С. 149-161.

4. Лузгин Б. Н. Рисунок речной сети Верхней Оби / Б. Н. Лузгин // География и природные ресурсы. - 2004. - № 3. - C. 96-101.

5. Лузгин Б. Н. Космическое отображение пойменно-русловых структур Верхней Оби / Б. Н. Лузгин // Исследования Земли из космоса. - 2010. - № 5. - С. 1-8.

6. Лузгин Б. Н. Пойменные акватории Верхней Оби / Б. Н. Лузгин // Известия Алтайского государственного университета. - 2010. - Вып. 3/2. - С. 93-98.

7. Лузгин Б. Н. Бассейново-эрозионный морфологический анализ Верхнеобской речной системы / Б. Н. Лузгин. - Барнаул : Издательство Алтайского государственного университета, 2009. - 120 с.

8. Львович М. И. Вода и жизнь / М. И. Львович. Москва : Мысль, 1986. - 254 с.

9. Малик Л. К. Гидротехнические сооружения в период войн и политических конфликтов / Л. К. Малик // Известия Российской академии наук. Серия географическая. - 2004. - № 2. - С. 83-91.

10. Панычев В. А. Радиоуглеродная хронология аллювиальных отложений Предалтайской равнины / В. А. Панычев. - Новосибирск : Наука, 1979. - 102 с.

11. Рейнек Г.-Э. Обстановки терригенного осадконакопления (с рассмотрением терригенных кластических осадков) / Г.-Э. Рейнек, И. Б. Сингх. - Москва : Недра, 1981. -439 с.

12. Русловые процессы и водные пути на реках Обского бассейна / под ред. Р. С. Чалова, Е. М. Плескевича, В. А. Баули. - Новосибирск : РИПЭЛ плюс, 2001. $-300 \mathrm{c}$.

13. Торнес Дж. Б. Геоморфология и время / Дж. Б. Торнес, Д. Брунсден. - Москва : Недра. 1981. 227 c.

14. Хакен Г. Синергетика. Иерархия устойчивостей в самоорганизующихся системах и устройствах / Г. Хакен. - Ленинград : Мир, 1985. - 419 с.

15. Чернов А. В. Палеогеографический анализ развития русловых формаций широкопойменных рек в голоцене (на примере среднего и верхнего течения р. О- би) / А. В. Чернов, Л. М. Гаррисон // Бюллетень московского общества испытателей природы. Отдел геологический. - 1981. - Вып. 4. - С. 97-108.

16. Шанцер Е. В. Аллювий равнинных рек умеренного пояса и его значение для познания закономерностей строения и формирования аллювиальных свит / Е. В. Шанцер. - Москва : Издательство АН СССР, 1951. -275 c.

\section{REFERENCES}

1. Adamenko O. M. Predaltayskaya vpadina i problemy formirovaniya predgornykh opuskaniy / O. M. Adamenko. - Novosibirsk : SO Nauka, 1976. - 184 s.

2. Devyataeva V. V. Ekzogennye geologicheskie protsessy na territorii Altayskogo kraya / V. V. Devyataeva // Geografiya i prirodopol'zovanie Sibiri. - 2001 . - Vyp. 4. S. 264-268.

3. Luzgin B. N. Parageneticheskie svyazi allyuvial'nykh i eolovykh protsessov v Verkhnem Priob'e / B. N. Luzgin // Geografiya i prirodopol'zovanie Sibiri. - 2009. - Vyp. 11. -S. 149-161.

4. Luzgin B. N. Risunok rechnoy seti Verkhney Obi / B. N. Luzgin // Geografiya i prirodnye resursy. - 2004. № 3. - S. 96-101.

5. Luzgin B. N. Kosmicheskoe otobrazhenie poymenno-ruslovykh struktur Verkhney Obi / B. N. Luzgin // Issledovaniya Zemli iz kosmosa. - 2010. - № 5. - S. 1-8.

6. Luzgin B. N. Poymennye akvatorii Verkhney Obi / B. N. Luzgin // Izvestiya Altayskogo gosudarstvennogo universiteta. - 2010. - Vyp. 3/2. - S. 93-98.

7. Luzgin B. N. Basseynovo-erozionnyy morfologicheskiy analiz Verkhneobskoy rechnoy sistemy / B. N. Luzgin. - Barnaul : Izdatel'stvo Altayskogo gosudarstvennogo universiteta, 2009. - 120 s.

8. L'vovich M. I. Voda i zhizn' / M. I. L'vovich. - Moskva : Mysl', 1986. - 254 s.

9. Malik L. K. Gidrotekhnicheskie sooruzheniya v period voyn i politicheskikh konfliktov / L. K. Malik // Izvestiya Rossiyskoy akademii nauk. Seriya geograficheskaya. - 2004. - № 2. - S. 83-91.

10. Panychev V. A. Radiouglerodnaya khronologiya allyuvial'nykh otlozheniy Predaltayskoy ravniny/ V. A. Panychev. - Novosibirsk : Nauka, 1979. - 102 s.

11. Reynek G.-E. Obstanovki terrigennogo osadkonakopleniya (s rassmotreniem terrigennykh klasticheskikh osadkov) / G.-E. Reynek, I. B. Singkh. - Moskva : Nedra, 1981. $-439 \mathrm{~s}$.

12. Ruslovye protsessy i vodnye puti na rekakh Obskogo basseyna / pod red. R. S. Chalova, E. M. Pleskevicha, V. A. Bauli. - Novosibirsk : RIPEL plyus, 2001. - 300 s.

13. Tornes Dzh. B. Geomorfologiya i vremya / Dzh. B. Tornes, D. Brunsden. - Moskva : Nedra. 1981. $227 \mathrm{~s}$.

14. Khaken G. Sinergetika. Ierarkhiya ustoychivostey v samoorganizuyushchikhsya sistemakh i ustroystvakh / G. Khaken. - Leningrad : Mir, 1985. -419 s. 
15. Chernov A. V. Paleogeograficheskiy analiz razvitiya ruslovykh formatsiy shirokopoymennykh rek v golotsene (na primere srednego i verkhnego techeniya r. Obi) / A. V. Chernov, L. M. Garrison // Byulleten' moskovskogo obshchestva ispytateley prirody. Otdel geologicheskiy. 1981. - Vyp. 4. - S. 97-108.

Лузгин Борис Николаевич

доктор географических наук, кандидат геолого-минералогических наук, профессор Алтайского государственного университета, г. Барнаул, E-mail: b.luzgin@mail.ru
16. Shantser E. V. Allyuviy ravninnykh rek umerennogo poyasa i ego znachenie dlya poznaniya zakonomernostey stroeniya i formirovaniya allyuvial'nykh svit / E. V. Shantser. - Moskva : Izdatel'stvo AN SSSR, 1951. - 275 s.

Luzgin Boris Nikolaevich

Doctor of Geographical Sciences, Candidate of Geological and Mineralogical Sciences, Professor of Altai State University, Barnaul, E-mail: b.luzgin@ mail.ru 